\title{
Characteristics and in-hospital outcomes of patients with acute coronary syndromes and heart failure in the United Arab Emirates
}

Abdulla Shehab ${ }^{1 * \dagger}$, Bayan Al-Dabbagh ${ }^{1{ }^{* \dagger}}$, Wael Almahmeed ${ }^{2}$, Nazar Bustani ${ }^{2}$, Nicolaas Nagelkerke ${ }^{3}$, Afzal Yusufali ${ }^{4}$, Adel Wassef ${ }^{5}$, Mohamed Ibrahim ${ }^{6}$ and Azan Bin Brek ${ }^{7}$

\begin{abstract}
Background: Heart failure (HF) is a serious complication of acute coronary syndromes (ACS), and is associated with high in-hospital mortality and poor long-term survival. The aims of this study were to describe the clinical characteristics, management and in-hospital outcomes of coronary syndrome (ACS) patients with HF in the United Arab Emirates.

Findings: The study was selected from the Gulf Registry of Acute Coronary Events (Gulf RACE), a prospective multi-national, multicenter registry of patients hospitalized with ACS in six Middle East countries. The present analysis was focused on participants admitted to various hospitals in the UAE with a diagnosis of ACS in 2007 and were analyzed in terms of HF (Killip class II/III and IV) on admission. Of 1691 patients (mean age: 52.6 \pm 11.7 years; 210 Females, 1481 Males) with ACS, 356 (21\%) had an admission diagnosis of HF (Killip class II/III and IV). HF patients were less frequently males (19.2\% vs. 34.3\%; $\mathrm{P}<0.001)$. HF was more frequently associated with hypertension (64.3\% vs. 43.9\%; $P<0.001$ ), hyperlipidemia (49.4\% vs. 31.8\%; $P<0.001$ ) and diabetes mellitus (DM) (51.1\% vs. 36.2\%; $P<0.001)$. HF was significantly associated with in-hospital mortality $(\mathrm{OR}=11.821 ; 95 \% \mathrm{Cl}: 5.385-25.948 ; \mathrm{P}<0.001)$. In multivariate logistic regression, age, hyperlipidemia, heart rate and DM were associated with higher in-hospital HF.
\end{abstract}

Conclusions: HF is observed in about 1 in 5 patients with ACS in the UAE and is associated with a significant increase in in-hospital mortality and other adverse outcomes.

Keywords: Heart failure, Acute coronary syndrome, United Arab Emirates

\section{Background}

Heart failure (HF) is a growing problem that puts a tremendous burden on health care facilities worldwide. Up to $70 \%$ of all patients with HF die within 5 years after their first hospital admission [1]. The most common cause of HF is coronary artery disease (CAD), including the acute coronary syndromes (ACS) of ST-segment elevation myocardial infarction (STEMI), non-STEMI (NSTEMI), and unstable angina (UA) [2]. The development of HF following ACS significantly worsens shortand long-term prognosis [3]. In developed countries, CAD is a major cause of HF, morbidity and mortality.

\footnotetext{
* Correspondence: a.shehab@uaeu.ac.ae; bayan.al-dabbagh@uaeu.ac.ae ${ }^{\dagger}$ Equal contributors

'Department of Internal Medicine, Faculty of Medicine and Health Sciences, United Arab Emirates University, Al Ain, United Arab Emirates

Full list of author information is available at the end of the article
}

Significant advances have been made over the last decade in therapeutic approaches to ACS, particularly the development of new antiplatelet therapies and recognition of the benefits of neurohumoral blockade. Nonetheless, ACS remains among the main causes of death in developing countries [3]. One factor contributing to the poor prognosis is development of HF and left ventricular dysfunction following myocardial infarction (MI) [4]. It is of utmost importance to identify patients at risk of developing HF at admission since it may influence immediate therapeutic choices and subsequent risk stratification strategies which consequently help improve prognosis, personalize patient care, optimize the use of healthcare resources and prevent HF and death.

The aim of this work was to describe the clinical characteristics, and in-hospital management/outcomes of

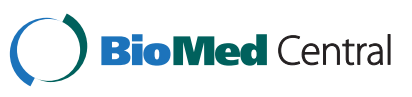


ACS patients with HF in the United Arab Emirates, enrolled in the Gulf Registry of Acute Coronary Events (Gulf RACE) [5,6]. We also evaluated HF impact on inhospital mortality.

\section{Methods}

\section{Patients and data collection}

Patients were selected from the Gulf Registry of Acute Coronary Events (Gulf RACE), a prospective multinational, multicentre registry of patients above 18 years of age hospitalized with the final diagnosis of ACS from various hospitals in 6 Middle Eastern countries, namely: Oman, United Arab Emirates (UAE), Qatar, Bahrain, Kuwait and Yemen [5]. Details of the Gulf RACE design and methods have been previously described [5]. There were no exclusion criteria. The recruitment in the pilot phase started from May 8, 2006, to June 6, 2006. Enrolment in the next phase of the registry started in January 29, 2007, and continued for 5 months till June 29, 2007. The present study included 1691 of 1697 patients hospitalized with an ACS across 18 hospitals in the UAE with complete data on HF (with HF: 356, 21.1\%). These hospitals care for more than $85 \%$ of patients with ACS in the country. Demographic, historical, and clinical data as well as in-hospital outcomes were recorded by study physicians for all patients admitted with a diagnosis of ACS.

Definitions of the sets of variables collected from the patients, outcome parameters as well as the diagnosis of ACS types were done following the American College of Cardiology (ACC) clinical data standards [7], for example:

1. DM: history of diabetes, regardless of duration of disease, need for antidiabetic agents, or a fasting blood sugar greater than $7 \mathrm{mmol} / \mathrm{l}$ or $126 \mathrm{mg} / \mathrm{dl}$.

2. Hypertension: documented by: 1 . History of hypertension diagnosed and treated with medication, diet, and/or exercise, 2. Blood pressure greater than $140 \mathrm{mmHg}$ systolic or $90 \mathrm{mmHg}$ diastolic on at least 2 occasions and 3. Current use of antihypertensive pharmacological therapy.

3. Hyperlipidemia: diagnosed and/or treated by a physician. National Cholesterol Education Program criteria include documentation of the following: 1 . Total cholesterol greater than $200 \mathrm{mg} / \mathrm{dl}(5.18 \mathrm{mmol} / \mathrm{l})$; or 2. Low-density lipoprotein (LDL) greater than or equal to $130 \mathrm{mg} / \mathrm{dl}(3.37 \mathrm{mmol} / \mathrm{l})$; or 3 . High-density lipoprotein (HDL) less than $40 \mathrm{mg} / \mathrm{dl}(1.04 \mathrm{mmol} / \mathrm{l})$. Treatment is also initiated if LDL is greater than $100 \mathrm{mg} / \mathrm{dl}(2.59 \mathrm{mmol} / \mathrm{l})$ in patients with known coronary artery disease, and this would qualify as hypercholesterolemia.

4. Past revascularization: including CABG or PCI of any type (balloon angioplasty, atherectomy, stent, or other) done before the current admission with the dates noted.

5. Prior CAD: includes history of angina before the current admission and if it existed more than 2 weeks before admission and/or within 2 weeks before admission. "Angina" refers to evidence or knowledge of symptoms before this acute event described as chest pain or pressure, jaw pain, arm pain, or other equivalent discomfort suggestive of cardiac ischemia. MI: the patient at least had 1 documented previous MI before admission with the date noted.

All the patients were assigned to one of the following categories: ST-elevation myocardial infarction (STEMI), nonST-segment elevation myocardial infarction (NSTEMI), left bundle branch block myocardial infarction (LBB MI) and UA. These definitions take into account clinical presentation, ECG findings, and the results of serum biochemical markers of myocardial necrosis (troponin and CPK-MB). Following ACS incidents after admissions, serial of cardiac enzymes were recorded and the highest (peak) values were used in our paper. Particularly, UA was defined as ACS with normal biochemical markers of necrosis. Patients were categorized at the time of hospital admission according to the classification of Killip and Kimball [8] for signs of HF. Killip class (scale I-IV) is a risk stratification tool for patients after acute myocardial infarction (AMI); a low Killip class indicates a lower likelihood of death within the first 30 days than a high Killip class. Smokers were defined as smoking cigarettes or sheesha (water pipe) within 1 month prior to index admission. A positive family history of coronary heart disease was defined as evidence of this disease in a parent, sibling, or children before the age of 55 years. The protocols of this study were approved by the $\mathrm{Al}$ Ain Medical District Human Research Ethics Committee, Abu Dhabi and Dubai Health Authorities and the Ministry of Health. All patients gave informed written consent to participate and care was taken to ensure data anonymity.

\section{Statistical analysis}

All data were analyzed with SPSS statistical software version 19.0 (Chicago, Illinois, USA). The comparison of continuous variables between patients with and without HF was performed using the Student t-test. Categorical variables were compared using the Pearson's chi-square test (or Fisher exact test for expected cells less than 5). Continuous variables with (approximately) normal distribution were expressed as mean $\pm \mathrm{SD}$. Multivariable backward stepwise logistic binary regression analysis was performed to estimate adjusted odds ratios (OR) of the potentially independent predictors (note: such predictors 
are not necessarily causes of outcome) of in-hospital HF adjusted for the following baseline covariates: age, gender, heart rate, smoking, DM, hypertension, hyperlipidemia, past revascularization including coronary artery bypasses graft surgery (CABG) or percutaneous coronary intervention (PCI) and prior coronary artery disease (CAD) including angina or myocardial infarction (MI).

Similarly, the association between HF and in-hospital mortality was examined using step-wise logistic regression models adjusting for the following covariates: age, gender, heart rate, smoking, DM, hypertension, hyperlipidemia, past revascularization including CABG or $\mathrm{PCI}$ and prior CAD including angina or MI. In all cases a P-value below 0.05 was considered statistically significant.

\section{Results}

\section{Patient population}

The records of 1691 ACS patients represent the total sample of this study. Among these, 356 patients (21.1\%) had HF at hospital admission. The clinical characteristics of the study sample, by HF diagnosis at hospital admission are shown in table 1. The mean age of the cohort was $52.5 \pm 11.6$ years. Patients with HF were significantly older than patients without HF $(57.8 \pm 13$ vs. $51.2 \pm 10.8$ years; $\mathrm{P}<0.001$ ), were less likely to be male (34.3\% among females vs. $19.2 \%$ among males; $\mathrm{P}<0.001$ ) and less likely to smoke ( $38.2 \%$ vs. $50.3 \%$; $\mathrm{P}<0.001)$. Risk factors for coronary artery disease were more common in patients with HF as they were more often hypertensive $(64.3 \%$ vs. $43.9 \%)$, hyperlipidemic $(49.4 \%$ vs. $31.8 \%)$ and diabetic $(51.1 \%$ vs. $36.2 \%)(\mathrm{P}<0.001$ for all comparisons). Furthermore, the HF group included a significantly higher number of patients with prior angina/MI and past $\mathrm{PCI} / \mathrm{CABG}$ ( $50 \%$ vs. $34.2 \%$; $\mathrm{P}<0.001,18.8 \%$ vs. $14.1 \% ; \mathrm{P}=0.018$, respectively) compared to the non-HF group. Patients with HF were slightly less likely to have STEMI on admission, but the overall distribution of admission diagnoses was not statistically different between HF and other patients. Patients with HF had a higher heart rate on presentation versus those without HF (97 \pm 27.2 vs. $81.4 \pm 19.8$ beats $/ \mathrm{min} ; \mathrm{P}<0.001)$.

\section{Medical management}

Table 2 outlines medication use and in-hospital management of the study patients. Compared with patients without HF, the use of aspirin, beta-blockers, calcium channel blockers, diuretics and subcutaneous insulin was significantly lower among patients with HF during their hospital treatment (Table 2). At discharge, the use of beta-blockers, calcium channel blockers, statins, nitrates, diuretics, antiarrythmic agents, digoxin and warfarin was significantly higher among patients with HF (Table 2). Moreover, Patients with HF were more likely to undergo invasive cardiac procedures than patients without HF.

\section{Predictors of HF}

Table 3 shows that the odds of HF increases by $3.4 \%$ per year of age $(\mathrm{OR}=1.034 ; 95 \% \mathrm{CI}: 1.021-1.047 ; \mathrm{P}<0.001)$. Furthermore, patients with a history of hyperlipidemia were 1.5 times $(\mathrm{OR}=1.539$; $95 \%$ CI: 1.096-2.162; $\mathrm{P}=0.013)$ more likely to present with HF than those without history of dyslipidemia. The risk of HF increased by $2.7 \%(\mathrm{OR}=1.027 ; 95 \% \mathrm{CI}: 1.021-1.034$; $\mathrm{P}<0.001)$, for every 1-beat-per-minute increase in heart rate. Finally, the model also showed that having diabetes mellitus (DM) increased the risk of HF by $42 \%(\mathrm{OR}=1.425 ; 95 \%$ CI: 1.047-1.938; $\mathrm{P}=0.024$ ).

\section{Heart failure and adverse outcomes including in-hospital mortality}

Major bleed $(n=15)$ and stroke $(n=9)$ were rare outcomes. Stroke was significantly associated with inhospital mortality, even after adjustment for HF $(\mathrm{P}<0.001)$. Table 4 indicates that HF was significantly associated with in-hospital mortality $(\mathrm{OR}=11.821$; $95 \%$ CI: 5.385-25.948; $\mathrm{P}<0.001)$. The in-hospital mortality rate for male patients was substantially lower than the mortality rate for female patients $(\mathrm{OR}=0.419 ; 95 \% \mathrm{CI}$ : 0.195-0.902; $\mathrm{P}<0.033$; using stepwise (backward selection) logistic regression).

\section{Discussion}

The overall incidence of HF complicating ACS in our study was $21 \%$ (less so in males which represented $87.6 \%$ of the study population). This rate of HF is lower than reported in some previous studies of HF after AMI $[9,10]$ but similar to several other ones [11-13]. Since there is no definitive diagnostic test for HF, these differences may well be due to varying definitions of HF among studies, exclusion criteria or as in the present study, inclusion of all patients with ACS, or could be due to different delays in seeking care thereby not receiving timely diagnosis or optimal therapies. It was observed that one in four ACS patients from six Middle Eastern countries in the entire GULF RACE cohort had HF [11]. In this study and using only the UAE data from the GULF RACE, we observed that one in five patients with ACS had HF during admission. This high rate of HF patients with ACS could be due to the high prevalence of DM in the region $[14,15]$. There is an increasing recognition that diabetic patients suffer from diabetic cardiomyopathy, including AMI and HF, which was originally described in 1972 on the basis of observations in four diabetic patients who presented with HF without evidence of hypertension, CAD, valvular or congenital heart disease [16]. Not surprisingly DM was also 
Table 1 Demographic and baseline characteristics of the studied acute coronary syndrome patients according to the presence of $\mathrm{HF}(n=1691)$

\begin{tabular}{|c|c|c|c|}
\hline Variable & $\begin{array}{c}\text { HF } \\
(n=356)\end{array}$ & $\begin{array}{c}\text { Non-HF } \\
(n=1335)\end{array}$ & P-value \\
\hline Age, mean $\pm S D$, years & $57.8 \pm 13.0$ & $51.2 \pm 10.8$ & $<0.001$ \\
\hline Male & $284(79.8)$ & $1197(89.7)$ & $<0.001$ \\
\hline Hypertension & $229(64.3)$ & $586(43.9)$ & $<0.001$ \\
\hline Hyperlipidemia & $176(49.4)$ & $425(31.8)$ & $<0.001$ \\
\hline Diabetes mellitus & $182(51.1)$ & $483(36.2)$ & $<0.001$ \\
\hline Smoking & $136(38.2)$ & $672(50.3)$ & $<0.001$ \\
\hline Family history of CAD & $39(11.0)$ & $221(16.6)$ & 0.008 \\
\hline Prior angina or Ml & $178(50.0)$ & $457(34.2)$ & $<0.001$ \\
\hline Past $\mathrm{PCl}$ or $\mathrm{CABG}$ & $67(18.8)$ & $188(14.1)$ & 0.030 \\
\hline ACS diagnosis: & & & 0.66 \\
\hline STEMI & $141(39.6)$ & $572(42.9)$ & \\
\hline NSTEMI & $81(22.8)$ & $302(22.6)$ & \\
\hline UA & $131(36.8)$ & $453(33.9)$ & \\
\hline LBBB MI & $3(0.8)$ & $8(0.6)$ & \\
\hline \multicolumn{4}{|l|}{ Admission characteristics: } \\
\hline \multicolumn{4}{|l|}{ Killip class: } \\
\hline 1 & - & $1335(100)$ & \\
\hline$\|$ & $221(62.0)$ & - & \\
\hline III & $102(28.7)$ & - & \\
\hline IV & $33(9.3)$ & - & \\
\hline ST deviation & $287(80.8)$ & 998 (749) & 0.021 \\
\hline Heart rate, mean $\pm S D$, beats/min & $97 \pm 27.2$ & $81.4 \pm 19.8$ & $<0.001$ \\
\hline Systolic blood pressure, mean \pm SD, $\mathrm{mm} \mathrm{Hg}$ & $145.7 \pm 40.5$ & $141.7 \pm 27.9$ & 0.028 \\
\hline Diastolic blood pressure, mean $\pm \mathrm{SD}, \mathrm{mm} \mathrm{Hg}$ & $87.2 \pm 23.7$ & $85.6 \pm 17.1$ & 0.167 \\
\hline \multicolumn{4}{|l|}{ Laboratory investigations ${ }^{*}$ : } \\
\hline Peak CPK, mean $\pm \mathrm{SD},(\mathrm{U} / \mathrm{l})$ & $1269.9 \pm 1930.5$ & $1295.2 \pm 1941.3$ & 0.167 \\
\hline Peak CPK-MB, mean \pm SD, (U/I) & $99.1 \pm 157.9$ & $96.4 \pm 135$ & 0.109 \\
\hline Peak troponin, mean $\pm \mathrm{SD},\left(\mu \mathrm{g} / \mathrm{l}^{\dagger}\right.$ & $19.2 \pm 79.3$ & $15.8 \pm 55.9$ & 0.581 \\
\hline Percent with LVEF $\leq 40 \%$ & 138/282 (49) & 700/959 (73) & $<0.001$ \\
\hline
\end{tabular}

*Values were $\log _{10}$ transformed to approximate normality for the independent sample t-test.

${ }^{\dagger}$ Peak troponin I or T (depending on recruiting centre).

Figures in parentheses are percentages.

Abbreviations: $H F$ heart failure, $S D$ standard deviation, $C A D$ coronary artery disease, $M I$ myocardial infarction, $P C I$ percutaneous coronary intervention, $C A B G$ coronary artery bypass surgery, NSTEMI non-ST-segment elevation myocardial infarction, STEMI ST-elevation myocardial infarction, LBBB left bundle branch block, $U A$ unstable angina, $C P K$ creatinine phosphokinase, $C P K-M B$ creatine kinase-myocardial band isoenzyme.

associated with HF in our study although our methodology precludes definitive causal interpretations. Most likely, because of the proinflammatory, and prothrombotic states associated with DM, diabetic patients with ACS are at high risk of subsequent cardiovascular events with poorer outcome and higher mortality rates [17-19]. This study also shows that HF is a common complication associated with all forms of ACS. Patients with ACS complicated by HF were more likely to die in the hospital or experience other in-hospital complications such as cardiogenic shock, infarction or stroke, although it is unclear from our logistic regression analyses whether this is because HF was the direct cause of in-hospital death (and other complications) in our patients or just a sign of substantial cardiac damage. Of note is that inhospital mortality in our study of HF patients was 7.3\%, which is relatively high. In-hospital mortality in large US registries was about $4 \%[20,21]$, whereas in the European registries it ranged from 3.8\% (ESC-HF Pilot) to 6.7\% (EHFS II) and 7.1\% (FINN-AKVA) [22-24]. There was a 
Table 2 In-hospital and discharge management of the studied ACS patients with and without HF $(n=1691)$

\begin{tabular}{|c|c|c|c|}
\hline & $\begin{array}{c}\text { HF } \\
(n=356)\end{array}$ & $\begin{array}{c}\text { Non-HF } \\
(n=1335)\end{array}$ & P-value \\
\hline \multicolumn{4}{|c|}{ In-hospital medical treatment: } \\
\hline Aspirin & $344(96.6)$ & $1328(99.5)$ & $<0.001$ \\
\hline Clopidogrel & $336(94.4)$ & $1290(96.6)$ & 0.06 \\
\hline IV HEP & $48(13.5)$ & $204(15.3)$ & 0.4 \\
\hline LMW HEP & $311(87.4)$ & $1154(86.4)$ & 0.72 \\
\hline GP & $132(37.1)$ & $534(40.0)$ & 0.32 \\
\hline $\mathrm{BB}$ & $156(43.8)$ & $995(74.5)$ & $<0.001$ \\
\hline ACE & $231(64.9)$ & $900(67.4)$ & 0.37 \\
\hline AllRB & $18(5.1)$ & $57(4.3)$ & 0.5 \\
\hline $\mathrm{CCB}$ & $40(11.2)$ & $98(7.3)$ & 0.022 \\
\hline Statins & $329(92.4)$ & $1268(95)$ & 0. \\
\hline Nitrates & $268(75.3)$ & $934(70.0)$ & 0.05 \\
\hline Diuretics & $242(68.0)$ & $158(11.8)$ & $<0.001$ \\
\hline SQ INS & $160(44.9)$ & $368(27.6)$ & $<0.00$ \\
\hline IV INS & $15(4.2)$ & $33(2.5)$ & 0.1 \\
\hline \multicolumn{4}{|c|}{ Discharge medical treatment: } \\
\hline Aspirin & $321(90.2)$ & $1293(97.0)$ & $<0.001$ \\
\hline Clopidogrel & $290(81.5)$ & $1105(82.8)$ & 0.8 \\
\hline BB & $258(72.5)$ & $1148(86.0)$ & $<0.00$ \\
\hline ACE & $252(70.8)$ & $999(74.8)$ & 0.1 \\
\hline AllRB & $30(8.4)$ & $84(6.3)$ & 0.15 \\
\hline $\mathrm{CCB}$ & $43(12.1)$ & $90(6.7)$ & 0.0 \\
\hline Statins & $320(90.9)$ & $1273(95.4)$ & 0.0 \\
\hline Nitrates & $181(51.0)$ & $543(40.7)$ & $<0.00$ \\
\hline Diuretics & $208(58.4)$ & $142(10.7)$ & $<0.0$ \\
\hline Antiarrythmic agents & $21(6.0)$ & $14(1.0)$ & $<0.001$ \\
\hline Digoxin & $16(4.5)$ & $6(0.4)$ & $<0.00$ \\
\hline Warfarin & $15(4.2)$ & $15(1.1)$ & $<0.00$ \\
\hline \multicolumn{4}{|l|}{ In-hospital procedures: } \\
\hline Echocardiography & $260(73.0)$ & $846(63.4)$ & 0.0 \\
\hline $\mathrm{PCl}$ & $9(2.5)$ & $13(1.0)$ & 0.025 \\
\hline IABP & $10(2.8)$ & $11(0.8)$ & 0.00 \\
\hline \multicolumn{4}{|l|}{ In-hospital outcomes: } \\
\hline Death & $26(7.3)$ & $8(0.6)$ & $<0.001$ \\
\hline Cardiogenic shock & $44(12.4)$ & $22(1.7)$ & $<0.00$ \\
\hline Infarction & $16(4.5)$ & $26(2.0)$ & 0.01 \\
\hline Stroke & $5(1.4)$ & $4(0.3)$ & 0.02 \\
\hline
\end{tabular}

Figures in parentheses are percentages.

Abbreviations: DM diabetes mellitus, IV HEP intravenous heparin, LMW HEP low molecular weight heparin, GP glycoprotein IIb/Illa inhibitors, $B B$ beta-blockers, $A C E$ angiotensin-converting enzyme inhibitors, $A$ IIIRB angiotensin II receptor blockers, CCB calcium channel blockers, SQ Insulin subcutaneous insulin, IV Insulin intravenous insulin, $P C l$ percutaneous coronary intervention, IABP Intra-aortic balloon pump.
Table 3 Independent predictors of in-hospital HF using multivariable logistic regression

\begin{tabular}{lllr}
\hline Criteria & OR & $\frac{\text { In-hospital HF }}{~}$ & P \\
\cline { 3 - 3 } & & $\mathbf{9 5 \%} \mathbf{C l}$ & \\
\hline Age & 1.034 & $1.021-1.047$ & $<0.001$ \\
hyperlipidemia & 1.539 & $1.096-2.162$ & 0.013 \\
Heart rate & 1.027 & $1.021-1.034$ & $<0.001$ \\
Prior CAD & 1.322 & $0.949-1.841$ & 0.100 \\
DM & 1.425 & $1.047-1.938$ & 0.024 \\
\hline
\end{tabular}

Abbreviation: $H F$ heart failure, $O R$ odds ratio, $C l$ confidence interval, $C A D$ coronary artery disease including angina or myocardial infarction (MI), DM diabetes mellitus.

The variables that were dropped out of the multivariable logistic regression using the stepwise-backward elimination method included gender, smoking, hypertension and past revascularization (CABG/PCI).

lower frequency of PCI and use of beta-blockers in the patients with HF. While the lower use of beta-blockers may be explained by the difficulty of starting such therapy early in patients with HF, the reason for the low rate of cardiac catheterization in these patients is uncertain.

The strengths of this investigation include its national perspective, the complete spectrum of ACSs experienced by the large number of patients studied and the use of standardized criteria for defining ACS and hospital outcomes. However, as with any observational registry-type study, the present findings have limitations. Although this registry includes 18 hospitals throughout the UAE, participating sites may not be representative of the whole country. Furthermore, post admission variables analyses related to physician discretion (medications, interventions) may be strongly influenced by unmeasured confounders. Our analysis is also limited by the lack of adequate follow up data on long term mortality and morbidity and it is possible that some patients were misclassified according to the Killip and Kimball [8] classification for signs of HF. Finally, the standard practice management of ACS in the participating hospitals were initially, predominantly conservative. There were few PCI facility centers and hardly any primary $\mathrm{PCI}$ center with an established interventional

Table 4 Relationship between HF and in-hospital mortality using multivariable logistic regression

\begin{tabular}{llcr}
\hline Criteria & OR & In-hospital mortality & P \\
\cline { 3 - 3 } & & $\mathbf{9 5 \% ~ C l}$ & \\
\hline HF & 11.821 & $5.385-25.948$ & $<0.001$ \\
Gender & 0.419 & $0.195-0.902$ & 0.033 \\
Heart rate & 1.013 & $1.000-1.026$ & 0.068 \\
\hline
\end{tabular}

Abbreviation: $\mathrm{HF}$ heart failure, $\mathrm{OR}$ odds ratio, $\mathrm{Cl}$ confidence interval. The variables that were dropped out of the multivariable logistic regression using the stepwise-backward elimination method included age, smoking, diabetes mellitus, hypertension, hyperlipidemia, past revascularization (CABG/PCI) and prior coronary artery disease (CAD) include angina or (MI). 
cardiology program (24 $\mathrm{h} / 7$ days) which has an important impact upon the incidence and severity of HF.

\section{Conclusions}

In conclusion, in this cohort of patients with ACS in the UAE, HF complicates one-fifth of cases and was associated with age, heart rate, hyperlipidemia and DM. In-hospital mortality rate was associated with HF and gender. Further studies are needed to better risk-stratify patients with HF for more analysis as well as having information about prior history of HF and outcomes of post-hospital discharge in order to optimize the use of medications and cardiovascular interventions for this serious condition.

\section{Competing interests}

The authors declare that they have no competing interests.

\section{Authors' contributions}

AS and BA performed data analysis and interpretation, critically reviewed the data analysis and wrote the paper. BA, NN, and AS performed the statistical analysis. WA and NB were involved in the inception and implementation and data collection of Gulf RACE in general and the UAE data. NN, AY, AW, MI and $A B$ were involved in the critical revision of the manuscript. All authors have read and approved the final version of the manuscript.

\section{Acknowledgments}

Gulf RACE is a Gulf Heart Association project. The authors gratefully acknowledge the financial support of Sanofi Aventis (Paris, France) and Qatar Telecommunications Company (Doha, Qatar). The funders had no role in study design, data collection and analysis, decision to publish, or preparation of the manuscript.

\section{Author details}

'Department of Internal Medicine, Faculty of Medicine and Health Sciences, United Arab Emirates University, Al Ain, United Arab Emirates. ${ }^{2}$ Heart and Vascular Institute, Sheikh Khalifa Medical City, Abu Dhabi, United Arab Emirates. ${ }^{3}$ Department of Community Medicine, Faculty of Medicine and Health Sciences, United Arab Emirates University, Al Ain, United Arab Emirates. ${ }^{4}$ Dubai Heart Centre, Dubai Hospital, Dubai, United Arab Emirates. ${ }^{5}$ Obaidallah Hospital (Saif Hospital), MOH, Ras Al-Khaimah, United Arab Emirates. ${ }^{6}$ Department of Cardiology, Kuwaiti Hospital, Sharjah, United Arab Emirates. ${ }^{7}$ Department of Cardiology, Rashid Hospital, Dubai, United Arab Emirates.

Received: 16 April 2012 Accepted: 19 September 2012 Published: 26 September 2012

\section{References}

1. Ko DT, Alter DA, Austin PC, You JJ, Lee DS, Qiu F, Stukel TA, Tu JV: Life expectancy after an index hospitalization for patients with heart failure: a population based study. Am Heart J 2008, 155:324-331.

2. Gheorghiade M, Bonow RO: Chronic heart failure in the United States: a manifestation of coronary artery disease. Circulation 1998, 97:282-289.

3. Hellermann JP, Jacobsen SJ, Gersh BJ, Rodeheffer RJ, Reeder GS, Roger VL: Heart failure after myocardial infarction: a review. Am J Med 2002, 113:324-30.

4. Spencer FA, Mayer TE, Goldberg RJ, Yarzebski J, Hatton M, Lessard D, Gore JM: Twenty-year trends (1975-1995) in the incidence, in-hospital and longterm death rates associated with heart failure complicating acute myocardial infarction: a community-wide perspective. J Am Coll Cardiol 1999, 34:1378-1387.

5. Zubaid M, Rashed WA, Al-Khaja N, Almahmeed W, Al-Lawati J, Sulaiman K, Al-Motarreb A, Amin H, Al-Suwaidi J, Al-Habib K: Clinical presentation and outcomes of acute coronary syndromes in the Gulf Registry of Acute Coronary Events (Gulf RACE). Saudi Med J 2008, 29:251-255.
6. Zubaid M, Rashed WA, Almahmeed W, Al-Lawati J, Sulaiman K, Al-Motarreb A, Amin H, Al Suwaidi J, AlHabib K: Management and outcomes of Middle Eastern patients admitted with acute coronary syndromes in the Gulf Registry of Acute Coronary Events (Gulf RACE). Acta Cardiologica 2009, 64:439-446.

7. Cannon CP, Battler A, Brindis RG, Cox JL, Ellis SG, Every NR, Flaherty JT, Harrington RA, Krumholz HM, Simoons ML, et al: American College of Cardiology key data elements and definitions for measuring the clinical management and outcomes of patients with acute coronary syndromes. A report of the American College of Cardiology Task Force on Clinical Data Standards (Acute Coronary Syndromes Writing Committee). J Am Coll Cardiol 2001, 38:2114-2130.

8. Killip T III, Kimball JT: Treatment of myocardial infarction in a coronary care unit: a two-year experience with 250 patients. Am J Cardiol 1967, 20:457-464.

9. Ali AS, Rybicki BA, Alam M, Wulbrecht N, Richer-Cornish K, Khaja F, Sabbah HN, Goldstein S: Clinical predictors of heart failure in patients with first acute myocardial infarction. Am Heart J 1999, 138:1133-1139.

10. Vaur L, Danchin N, Genès N, Dubroca I, Etienne S, Ferrières J, Cambou JP: Epidemiology of myocardial infarction in France: therapeutic and prognostic implications of heart failure during the acute phase. Am Heart J 1999, 137:49-58.

11. Alsheikh-Ali AA, Al-Mallah MH, Al-Mahmeed W, Albustani N, Al Suwaidi J, Sulaiman K, Zubaid M: Gulf RACE Investigators. Heart failure in patients hospitalized with acute coronary syndromes: observations from the Gulf Registry of Acute Coronary Events (Gulf RACE). Eur J Heart Fail 2009, 11:1135-1142.

12. Hasdai D, Topol EJ, Kilaru R, Battler A, Harrington RA, Vahanian A, Ohman EM, Granger CB, Van de Werf F, Simoons ML, et al: Frequency, patient characteristics, and outcomes of mild-to-moderate heart failure complicating ST-segment elevation acute myocardial infarction: lessons from 4 international fibrinolytic therapy trials. Am Heart $J$ 2003, 145:73-79.

13. Spencer FA, Meyer TE, Gore JM, Goldberg RJ: Heterogeneity in the management and outcomes of patients with acute myocardial infarction complicated by heart failure: the National Registry of Myocardial Infarction. Circulation 2002, 105:2605-2610.

14. Saadi H, Carruthers SG, Nagelkerke N, Al-Maskari F, Afandi B, Reed R, Lukic M, Nicholls MG, Kazam E, Algawi K, et al: Prevalence of diabetes mellitus and its complications in a population-based sample in Al Ain, United Arab Emirates. Diabetes Res Clin Pract 2007, 78:369-377.

15. Malik M, Bakir A, Abi Saab B, Roglic G, King H: Glucose intolerance and associated factors in the multiethnic population of the United Arab Emirates: results of a national survey. Diabetes Res and Clin Pract 2005, 69:188-195.

16. Rubler S, Dlugash J, Yuceoglu YZ, Kumral T, Branwood AW, Grishman A: New type of cardiomyopathy associated with diabetic glomerulosclerosis. Am J Cardiol 1972, 30:595-602.

17. Donahoe SM, Stewart GC, McCabe CH, Mohanavelu S, Murphy SA, Cannon $\mathrm{CP}$, Antman EM: Diabetes and mortality following acute coronary syndromes. JAMA 2007, 298:765-775.

18. Hildebrandt P: Diabetic patients and acute coronary syndromes. Eur Heart J 2001, 22:887-888.

19. Franklin K, Goldberg RJ, Spencer F, Klein W, Budaj A, Brieger D, Marre M, Steg PG, Gowda N, Gore JM, et al: Implications of diabetes in patients with acute coronary syndromes. The Global Registry of Acute Coronary Events. Arch Intern Med 2004, 164:1457-1463.

20. Abraham TW, Fonarow GC, Albert NM, Stough WG, Gheorghiade M, Greenberg BH, O'Connor CM, Sun JL, Yancy CW, Young JB, et al: Predictors of In-Hospital Mortality in Patients Hospitalized for Heart Failure: Insights From the Organized Program to Initiate Lifesaving Treatment in Hospitalized Patients With Heart Failure (OPTIMIZE-HF). J Am Coll Cardiol 2008, 52:347-356.

21. Fonarow GC, Adams KF Jr, Abraham WT, Yancy CW, Boscardin WJ: ADHERE Scientific Advisory Committee, Study Group, and Investigators: Risk stratification for in-hospital mortality in acutely decompensated heart failure: classification and regression tree analysis. JAMA 2005, 293:572-580.

22. Maggioni AP, Dahlström U, Filippatos G, Chioncel O, Leiro MC, Drozdz J, Fruhwald F, Gullestad L, Logeart D, Metra M, et al: EURObservational Research Programme: the Heart Failure Pilot Survey (ESC-HF Pilot). Eur J Heart Fail 2010, 12:1076-1084. 
23. Nieminen MS, Brutsaert D, Dickstein K, Drexler H, Follath F, Harjola VP, Hochadel M, Komajda M, Lassus J, Lopez-Sendon JL, et al: EuroHeart Failure Survey II (EHFS II): a survey on hospitalized acute heart failure patients: description of population. Eur Heart J 2006, 27:2725-2736.

24. Siirila-Waris K, Lassus J, Melin J, Peuhkurinen K, Nieminen MS, Harjola V FINN-AKVA Study Group: Characteristics, outcomes, and predictors of 1-year mortality in patients hospitalized for acute heart failure. Eur Heart J 2006, 27:3011-3017.

doi:10.1186/1756-0500-5-534

Cite this article as: Shehab et al:: Characteristics and in-hospital

outcomes of patients with acute coronary syndromes and heart failure

in the United Arab Emirates. BMC Research Notes 2012 5:534.

\section{Submit your next manuscript to BioMed Central and take full advantage of:}

- Convenient online submission

- Thorough peer review

- No space constraints or color figure charges

- Immediate publication on acceptance

- Inclusion in PubMed, CAS, Scopus and Google Scholar

- Research which is freely available for redistribution 